\title{
On Terms
}

\author{
Determinism 1 \\ Jack Marr \\ Georgia Institute of Technology
}

Anyone who has taught introductory psychology (especially at a technological institution) has been faced by a significant number of students who cannot believe that psychology is, or could ever be, a science. Some time may be spent attempting to convince the skeptics that a science of behavior can indeed exist and take its rightful place with biology, chemistry, and even physics. As behavior analysts we have been imbued with a deterministic perspective that, on the surface, does not appear significantly different from that of classical physics. This traditional stance is exemplified by Skinner's declaration in Science and Human Behavior:

If we are to use the methods of science in the field of human affairs, we must assume behavior is lawful and determined. We must expect to discover what a man does is the result of specifiable conditions and that once these conditions have been discovered, we can anticipate and to some extent determine his actions $(1953$, p. 6).

Although this statement seems clear enough, a more thorough analysis of the behaviorist's principles and practices reveals a complex picture which is in some ways more reflective of the physics of Bohr and Heisenberg, than of Newton and Laplace.

The radical behaviorist position on the issues of determinism and causality has been a matter of debate, e.g., Vorsteg (1974), Begelman (1978) and Day (1969). The latter stated explicitly:

The practice of looking for functional relationships is obviously similar in certain respects to the effort to find relations between cause and effect. Yet

\footnotetext{
'Portions of this paper have been presented at the Association for Behavioral Analysis, Milwaukee, Wisconsin, May, 1981, and the Symposium on Science and Human Behavior, Mexico City, February, 1981. Requests for reprints should be sent to Jack Marr, School of Psychology, Georgia Institute of Technology, Atlanta, GA 30332.
}

in attempting to discover functional relationships the radical behaviorist does not accept any a priori logical assumption of a universe that is orderly in a mechanical sense upon which he feels he must base his scientific work (Day, 1969, p. 318).

The concept of probability of a response is central to the theoretical framework. Yet, it is unclear whether this probabilistic approach reflects only a practical lack of specifiability in initial conditions or reflects, at least in part, random processes controlling the emission of behavior. In a recent presentation of Skinnerian theory, Catania (1980) remarks "Admitting the possibility that behavior could occur spontaneously was a critical conceptual step in operant theory" (p. 138, my italics). Skinner (1974) says it this way:

To distinguish an operant from an elicited reflex we say that the operant is emitted. (It might be better to say simply that behavior exists inside the organism and then comes out. But the word need not mean ejection; light is not in the hot filament before it is emitted). The principal feature is that there seems to be no necessary prior causal event (p. 53, my italics).

Quantum physics provides numerous analogous processes. In radioactive decay, for example, events occur at random; one can only assign measures (e.g., the half-life) to aggregates. An example is beta decay. In its simplest form a neutron is "converted" into a proton, a neutrino, and an electron (the beta particle). It is important to emphasize that the neutron is not made up of these three "products," i.e., these particles are not inside a bag which we call the neutron. They simply appear-at random. So far as I know, there is no way physicists can exert practical control over processes like radioactive decay. They cannot, for example, change the half-life of strontium-90. However, it is a defining property of conditioning that certain experimental ar- 
rangements can change the probability of behavior. In spite of their spontaneity, operants, unlike atoms, have a "sense of history." Indeed, alteration in the frequency and organization of behavior through conditioning is one very significant example of an irreversible biological process that provides an "arrow of time" (Pagels, 1982, Prigogine, 1980).

That spontaneity may be a characteristic feature of behavior can provide no solace for those who would champion "free will." Spontaneity implies that the emitted behavior is no more under the control of the emitter than it is under the control of the observer. It would be as absurd to ascribe "free will" to a pigeon or a human as it would to a neutron emitting a beta particle. Spontaneity also does not imply that simply anything can occur. Just as microphysical processes are limited by kind and distribution, so species membership and individual genetic endowment set natural limits to the form and variability of spontaneously emitted behavior.

It could be argued that behavior analysts are really only interested in behavior once it has been emitted. Never mind where it comes from; what happens when it does occur is the important question. But even here we have by no means left the domain of the random.

Random variations in behavior are clearly revealed even under the highly controlled conditions used to study reinforcement contingencies. For example, pause times and response numbers engendered by fixed-interval schedules appear to be randomly distributed. One is only able to predict the average values of output (Zeiler, 1979), just as the physicist must be content with determining the average values of position and momentum of an atomic entity. Furthermore, as Zeiler and his colleagues have shown, output under fixed-interval schedules is "not a directly reinforceable property of behavior"' (p. 113). Attempts to control output by differential reinforcement are unsuccessful. This example not only illustrates that behavior may be emitted in a random way and that it may not be directly controllable by reinforcement procedures, but it also leads me to consider briefly how our processes of observation may interact in a significant way with what is observed.

Classically speaking, observations are made to determine the state of a system. Given appropiate functional relationships we could predict future (and past) states of a system to an arbitrary degree of precision. This account is based upon the assumption that observation, i.e., measurement, of the state contributes nothing to the state. In quantum physics, however, one may have to contend with measurement processes in which this assumption cannot hold. This situation is one facet of the Heisenberg Principle of Indeterminancy. While I will not venture to conclude that any aspect of behavior results from processes reflective of the probabilistic nature of quantum physics (although an argument could be advanced; see, e.g., Mercer, 1981), there are features of the analysis of behavior which yield analogous problems of measurement. In particular, I have pointed out elsewhere (Marr, 1979) that in attempting to isolate determinants of schedule performance, the typical tactic is to alter the schedule. For example, Zeiler (1977) suggests that to evaluate the role of indirect variables in determining schedule performance, one should impose that variable directly. Changing an indirect variable to a direct one will likely change performance, but it will not necessarily tell us how, or even if, that variable exerts its effects indirectly.

A similar problem arises when schedule performance is analyzed in terms of the discriminative properties of behavior. It is possible to show that responding generated under a fixed-interval schedule may acquire discriminative properties (Buchman and Zeiler, 1975); however, stimulus control by response number does not affect the output itself. Again, assessing the role of the discriminative properties of behavior in controlling schedule performance requires the imposition of new contingencies, and definitive conclusions are elusive. Schedule performance appears to be the outcome of the interactions of a number of dynamic 
variables-we cannot seem to apprehend the organization of these processes by changing them. As P. C. W. Davies says of such analytic approaches in physics: "There seems to be a kind of uncertainty principle which says that one cannot simultaneously determine how matter works and what it is made of. The very act of investigating its structure inevitably destroys its organization"' (1979, p. 230).

The abandonment of mechanistic determinism should not be viewed by behaviorists with despair, but rather be looked upon as liberating (as it has been for physics). The element of spontaneity coupled with the malleable but metastable character of contingencies are probably essential to the emergence of complex behavior (Epstein, 1981).

\section{REFERENCE NOTES}

Begelman, P. A. Skinner's determinism. Behaviorism, 1978, 6, 13-25.

Buchman, J. B. and Zeiler, M. D. Stimulus properties of fixed-interval responses. Journal of the Experimental Analysis of Behavior, 1975, 24, 369-375.

Davies, P. C. W. The forces of nature. Cambridge: Cambridge University Press, 1979.

Day, W. Radical behaviorism in reconciliation with phenomenology. Journal of the Experimental Analysis of Behavior, 1969, 12, 315-328.

Epstein, R. On pigeons and people: A prelimi- nary look at the Columban simulation project. The Behavior Analyst, 1981, 4, 43-55.

Catania, A. C. Operant theory: Skinner. In A. M. Gazda \& R. J. Corsini (Eds.) Theories of learning: A comparative approach. Itasca, Ill.: F. E. Peacock Publishers, Inc., 1980.

Marr, M. J. Second-order schedules and the generation of unitary response sequences. In M. D. Zeiler and P. Harzem (Eds.) Advances in the analysis of behavior (Vol. I) Reinforcement and the organization of behavior. Chichester: John Wiley and Sons, 1979, 223-260.

Mercer, E. H. The foundations of biological theory. New York: John Wiley and Sons, 1981.

Pagels, H. R. The cosmic code. N.Y.: Simon and Schuster, 1982.

Prigogine, I. From being to becoming. San Francisco: W. H. Freeman, 1980.

Shimp, C. The local organization of behavior: Method and theory. In M. D. Zeiler \& P. Harzem (Eds.) Advances in the analysis of behavior (Vol. I) Reinforcement and the organization of behavior. Chichester: John Wiley and Sons, 1979, 261-295.

Skinner, B. F. Science and human behavior. New York: Macmillan, 1953.

Skinner, B. F. About behaviorism. New York: Alfred A. Knopf, 1974.

Vorsteg, R. H. Operant reinforcement theory and determinism. Behaviorism, 1974, 2, 108-119.

Zeiler, M. D. Schedules of reinforcement: The controlling variables. In W. R. Honig \& J. E. R. Staddon (Eds.) Handbook of operant behavior. Englewood Cliffs, N.J.: Prentice-Hall, Inc., 1977, 201-232.

Zeiler, M. D. Output dynamics. In M. D. Zeiler \& P. Harzem (Eds.) Advances in the analysis of behavior (Vol. I) Reinforcement and the organization of behavior. Chichester: John Wiley and Sons, 1979, 79-115. 